\title{
Reflexões sobre Práticas e Cotidiano Institucional na Rede de Proteção à Mulher
}

\author{
Victor Hugo Belarmino ${ }^{1}$ \\ ${ }^{1}$ Universidade Federal do Rio Grande do Norte, RN, \\ Brasil. \\ Letícia Lívia de Araújo Santos ${ }^{1}$ \\ ${ }^{1}$ Universidade Federal do Rio Grande do Norte, $R N$, \\ Brasil.
}

\author{
Janine Conceição de Araújo e Silva ${ }^{1}$ \\ ${ }^{1}$ Universidade Federal do Rio Grande do Norte, RN, \\ Brasil. \\ Magda Dimenstein ${ }^{1}$ \\ ${ }^{1}$ Universidade Federal do Rio Grande do Norte, RN, \\ Brasil.
}

Resumo: Esse artigo é o relato de uma experiência de estágio curricular em Psicologia na Rede de Proteção à Mulher da cidade de Natal (RN). O objetivo consiste em refletir acerca do seu funcionamento institucional, com ênfase nas práticas profissionais, a partir de três eixos norteadores: 1. aspectos institucionais e operacionais da rede de proteção; 2. Articulação e fluxos intra/intersetoriais na rede de atenção local; 3. Práticas profissionais, com ênfase no cotidiano dos serviços. Para tanto, foi utilizado o referencial teórico da Análise Institucional para pensar os serviços e o trabalho dos agentes no cotidiano. Durante o período em questão foi possível constatar a fragilidade do funcionamento em rede, tanto em nível setorial, quanto intersetorial, revelando a desarticulação dos serviços e pouca fluidez do fluxo assistencial. Ademais, percebeu-se a atuação profissional ainda marcada por estereótipos de gênero, práticas prescritivas e posturas moralistas, assentadas no dualismo vítima-agressor. Portanto, faz-se essencial o aprimoramento das políticas públicas já existentes, tornando-as mais abrangentes e efetivas, fortalecendo, desse modo, o funcionamento em rede. Importante destacar a necessidade de projetos de formação continuada visando qualificar a atenção prestada às mulheres vítimas de violência.

Palavras-chave: Violência, Gênero, Rede de Proteção à Mulher, Análise Institucional.

\section{Reflections on Practices and the Institutional Daily Life in the Women's Protection Network}

\begin{abstract}
This article is the report of an experience of curricular internship in Psychology in the Women's Protection Network of the city of Natal (RN). The objective is to reflect on the institutional functioning of the network, with emphasis on professional practices, based on three guiding axes: 1. institutional and operational aspects of the protection network; 2 . Articulation and intra/intersectoral flows in the local health care network; 3. Professional practices, with an emphasis on daily services. For that, the theoretical reference of the Institutional Analysis was used to think about the services and the work of the agents in the daily life. During the period in question, it was possible to verify the fragility of the network operation, both at sectoral and intersectoral levels, revealing the disarticulation of services and little fluidity of the care flow. In addition, it was noticed that the professional performance is still marked by gender stereotypes, prescriptive practices and moralist attitudes, based on the victim-aggressor dualism. Therefore, it is essential to improve existing public policies, making them more comprehensive and effective, thus strengthening networking. It is important to highlight the need for ongoing training projects aimed at qualifying the attention given to women victims of violence.
\end{abstract}

Keywords: Violence, Gender, Women's Protection Network, Institutional Analysis. 


\title{
Reflexiones sobre Prácticas y Vida Cotidiana Institucional en la Red de Protección a la Mujer
}

\begin{abstract}
Resumen: Este artículo es el informe de una experiencia de pasantía curricular en Psicología en la Red de Protección de la Mujer en la ciudad de Natal (RN). El objetivo es reflexionar sobre su funcionamiento institucional, con énfasis en las prácticas profesionales, basadas en 3 ejes rectores: 1. Aspectos institucionales y operativos de la red de seguridad; 2 . Articulación y flujos intra / intersectoriales en la red de atención local; 3. Prácticas profesionales, con énfasis en los servicios diarios. Para ello, se utilizó el marco teórico del Análisis Institucional para pensar sobre los servicios y el trabajo de los agentes en la vida cotidiana. Durante el período en cuestión, fue posible observar la fragilidad de la operación de la red, tanto a nivel sectorial como intersectorial, revelando la desarticulación de los servicios y la poca fluidez en el flujo de asistencia. Además, se observó que el desempeño profesional todavía está marcado por los estereotipos de género, las prácticas prescriptivas y las actitudes moralistas, basadas en el dualismo víctima-agresor. Por lo tanto, es esencial mejorar las políticas públicas existentes, haciéndolas más integrales y efectivas, fortaleciendo así el funcionamiento de la red. Es importante resaltar la necesidad de proyectos de educación continuada destinados a mejorar la atención brindada a las mujeres víctimas de violencia.
\end{abstract}

Palabras clave: Violencia, Género, Red de Protección a la Mujer, Análisis Institucional.

\section{Introdução}

Este artigo trata-se de um relato de experiência em estágio curricular do curso de Psicologia pela Universidade Federal do Rio Grande do Norte (UFRN), ao longo do ano de 2016. O estágio de conclusão de curso em questão consistiu em uma prática supervisionada, com cumprimento de carga horária semanal de 20 h, compondo o montante de $300 \mathrm{~h} / \mathrm{ano}$. O estágio de ênfase visa o amplo desenvolvimento das competências específicas da habilitação profissional, portanto, ultrapassa as expectativas próprias dos estágios básicos voltados à observação, simulação em situações controladas de atividades e elaboração de diagnóstico de situações clínicas.

Os campos de práticas vivenciados foram um Centro de Referência e uma Casa Abrigo, ambos vinculados à Secretaria de Políticas Públicas para Mulheres (Semul) do município de Natal (RN). Dentre as atividades desempenhadas destacaram-se: atendimentos psicossociais, acompanhamentos psicológicos, visitas domiciliares e condução de grupo terapêutico - atividades direcionadas à escuta, acolhimento, reflexão e orientação das mulheres em sofrimento, assim como aquelas de cunho intersetorial a partir da articulação com outros âmbitos como é o caso das Secretaria de Saúde, de Educação e Segurança Pública. Todas elas foram rigorosamente registradas em diário de campo, de onde provêm os principais apontamentos aqui discutidos.

Pretendemos nesse artigo analisar o funcionamento da rede local de proteção à mulher, bem como as práticas de acolhimento desenvolvidas no cotidiano dos serviços, no intuito de qualificar a atenção às mulheres vítimas de violência. Para tanto, a perspectiva da Análise Institucional se mostra potente, uma vez que, como definem Santos, Souza e Santos (2001), está interessada, do ponto de vista teórico e metodológico, nas relações institucionais dos diferentes grupos de sujeitos, tanto no que diz respeito aos modos de apropriação, usos, transformações de dispositivos, estruturas, quanto em relação às negociações e dinâmicas de poder. Inspirando-se em Baremblit (2002), tomar essa rede e serviços como campo de análise, significa que os mesmos estão sendo compreendidos enquanto um recorte da vida social, portanto, reveladores de suas tramas a partir de seu funcionamento, de suas determinações e de efeitos.

Em termos organizativos, este artigo está estruturado em três eixos norteadores: 1 . Aspectos institucionais e operacionais da rede de proteção; 2. Articulação e fluxos intra/intersetoriais na rede de atenção local; 3. Práticas profissionais, com ênfase no cotidiano dos 
serviços. Esse último ponto terá um aprofundamento a partir da subdivisão em três aspectos: a) práticas normativas e ideais de eficácia; b) embates da prática psicológica e social, e c) empoderamento e manejo do sofrimento no cotidiano. Contudo, iniciaremos contextualizando nosso campo problemático e o cenário de práticas.

\section{Alguns apontamentos acerca da temática "violência contra a mulher"}

De acordo com Romagnoli (2015), violência de gênero tem se apresentado como um conceito amplo e polêmico, o qual comporta diversas leituras, já que precisa equacionar questões como intencionalidade e legitimidade, bem como as variações culturais que implicam necessariamente em diferentes significados em relação aos atos e/ou atitudes violentas. Piosiadlo, Fonseca e Gessner (2014), por sua vez, sinalizam que o processo de predicação do que se nomina por violência pode variar de acordo com os agentes, com a população atingida ou com o local em que acontece - sendo estes parâmetros os mais utilizados nas políticas e produções da área. Neste artigo será adotada a definição proposta na Convenção Interamericana para Prevenir, Punir e Erradicar a Violência Contra a Mulher como sendo "qualquer ato ou conduta baseada no gênero, que cause morte, dano ou sofrimento físico, sexual ou psicológico à mulher, tanto na esfera pública como na esfera privada" (OEA, 1994, p. 1).

A violência contra as mulheres é uma das facetas da violência de gênero. Romagnoli (2015) aponta que se trata um problema social e de saúde pública, uma vez que gera elevado ônus para o sistema de saúde - calculado em termos de mortalidade/morbidade, qualidade de vida e custo -; afeta principalmente as minorias e os indivíduos desfavorecidos; e há sólidas evidências de que é possível reduzir os índices através de estratégias eficazes de prevenção. A Organização Mundial de Saúde (WHO, 2013), por sua vez, confirma que esta violência se configura um problema de saúde pública global, posto que afeta quase um terço das mulheres em todo o mundo. Nesse sentido, estima-se que $35 \%$ das mulheres no planeta já sofreram violência física e/ou sexual, em sua maioria praticada por parceiro íntimo - 38\% dos assassinatos de mulheres foram de sua autoria.

Apesar de a violência ocorrer contra mulheres de todas as idades, classe social, cultura, grau de instrução, etnia e grau de desenvolvimento do país (Moura,
Netto, \& Souza, 2012), estudos descritivos recentes (Barufaldi et al., 2017; Rafael et al., 2017) demonstram o atravessamento das questões de classe, raça e etnia nas situações de violência, ou seja, mulheres negras, de menor escolaridade e com piores condições de vida foram as principais vítimas de violência e homicídios.

\section{Contextualizando o cenário do estágio na rede de enfrentamento à violência contra a mulher}

Natal - capital do estado do Rio Grande do Norte, na região Nordeste do Brasil - ocupa lugar de destaque nos índices de crescimento das taxas de homicídios de mulheres. De acordo com o Mapa da Violência (Waiselfisz, 2015) foi a $4^{\text {a }}$ cidade com maior número de homicídios de mulheres na região entre 2003 e 2013, sendo a capital brasileira que apresentou maior crescimento nas taxas de homicídios de mulheres no mesmo período. Em nível estadual, o Rio Grande do Norte ocupa o $17^{\circ}$ lugar nas taxas de mortalidade de mulheres por agressões dentre as Unidades da Federação, segundo dados do Perfil das Mortes de Mulheres por Agressão, traçado pelo Instituto de Pesquisa Econômica Aplicada (Garcia, \& Silva, 2016). Dados do último relatório produzido pelo Instituto de Pesquisa Econômica Aplicada (Ipea) no Atlas da Violência (Cerqueira et al., 2018), o qual traz informações acerca dos números de feminicídios, revelam que somente em 2016, 4.645 mulheres foram assassinadas no Brasil, correspondendo a 4,5 mortes para cada 100 mil mulheres. O estado do Rio Grande do Norte foi um dos que apresentou maiores taxas de aumento nos últimos 10 anos, da ordem de 130,0\%. Os dados deste relatório confirmam ainda o componente racial no número de feminicídio: enquanto a mortalidade de mulheres não negras teve uma redução de 8,0\% entre 2006 e 2016, atingindo 3,1 mortes para cada 100 mil mulheres não negras, a mortalidade de mulheres negras apresentou aumento de $15,4 \%$ no mesmo período, chegando à taxa de 5,3 mortes para cada $100 \mathrm{mil}$ mulheres negras.

No município de Natal, todavia, inexistia um sistema de informação oficial acerca do perfil das mulheres vítimas de violência. Os estagiários do curso de Psicologia da UFRN organizaram um banco de dados, preenchido a partir das fichas psicossociais de atendimento. Foram cadastradas 443 mulheres, desde 2013 até a finalização do estágio, em dezem- 
bro de 2016. Nesse artigo, tomaremos como fonte de análise os dados desse banco, bem como as informações advindas das atividades realizadas na instituição, desde os atendimentos clínicos, visitas domiciliares, até as reuniões em equipe e articulação intersetorial.

Em primeiro lugar, a análise descritiva dos dados demonstra que a demanda acolhida pelo Centro de Referência e pela Casa Abrigo corresponde aos casos de mulheres residentes no município e região metropolitana, a partir de encaminhamentos de diversos pontos da rede de proteção à mulher, bem como de outros setores. O maior percentual de atendimentos é proveniente da Delegacia Especializada de Atendimento à Mulher da Zona Norte (DEAM-ZN) - situada em um território de elevada vulnerabilidade social, onde também se localiza o Centro de Referência.

A maior parte das usuárias tinha entre 19 e 40 anos; indicou cor parda; tinha Ensino Fundamental Incompleto ou Ensino Médio Completo e estava em união estável. Sobre a situação socioeconômica, a maioria encontrava-se desempregada e sem renda. Apesar disso, quase a metade não recebia qualquer benefício social. Sobre o perfil da violência sofrida, mais da metade das mulheres afirmou ter sofrido mais de um tipo violência, perpetrada pelo atual parceiro e na residência de ambos e o ciúme foi a causa mais atribuída para a violência. Esse perfil condiz com os dados da população feminina no Brasil apresentados pelo Instituto de Pesquisa DataSenado (Brasil, 2017). A seguir, discutiremos o funcionamento institucional com ênfase nas práticas profissionais.

\section{Aspectos estruturais e operacionais do Centro de Referência e da Casa Abrigo}

O período de realização do estágio coincidiu com a transição de equipes, efeito de uma ampla substituição dos profissionais contratados e cedidos pela Secretaria Municipal do Trabalho e da Assistência Social (Semtas), por profissionais oriundos de concurso público. Por um lado, o vínculo de trabalho temporário produzia na antiga equipe desmotivação e dificuldade para o desenvolvimento de intervenções contínuas, semelhante ao encontrado por Andrade e Morais (2017). Por outro lado, os profissionais recém-contratados destacavam a insuficiência da capacitação recebida para se apropriarem dos processos de trabalho e manejarem os casos, gerando insegurança na prática cotidiana. Essa substituição abrupta provocou uma forte oscilação no qua- dro técnico, suprimindo, por um longo período de tempo, profissionais importantes como vigia, auxiliar de serviços gerais (ASG), educador e advogado: este último, agente indispensável na atenção às demandas das mulheres, já que em muitos casos a própria procura pelo centro de referência ocorria em função do acompanhamento jurídico e, só posteriormente, as mulheres buscavam por outros serviços, como o acompanhamento psicológico.

Embora a capacitação e formação continuada estejam preconizadas nas normas técnicas (Brasil, 2006, 2011a), consoante Pasinato (2015), sua não efetivação produz supervalorização de conhecimentos protocolares, reproduzidos mecanicamente no cotidiano e desvinculados de bases teóricas e conceituais determinantes para entendimento mais amplo da violência e, consequentemente, do acolhimento à mulher. $\mathrm{O}$ estudo feito por Carmo-Souza e Faria (2017) encontrou elevada frequência de profissionais na faixa etária acima de 45 anos, que trabalham na rede de atendimento à mulher, entretanto, com pouco tempo de experiência profissional no tema da violência. Apesar desse cenário, a revisão sistemática realizada por Krenkel e Moré (2017) revela serem escassos os estudos direcionados à prática ou à intervenção desses profissionais, ainda que diariamente lidem com um tema que pode gerar mobilização e impactos na sua atuação.

Andrade e Morais (2017) ressaltam que aspectos como preparo acadêmico, capacitação continuada, maiores investimentos no setor público e fortalecimento dos recursos humanos são fatores imprescindíveis na implementação e execução da "verdadeira" política de assistência social. Trentin et al. (2018) complementam que, para além de um comprometimento pessoal dos envolvidos no atendimento, é imperativo haver a instrumentalização profissional, passando desde a formação acadêmica até a prática profissional por meio de educação permanente e supervisão local.

\section{Articulação e fluxos intra e intersetoriais na rede de atenção local}

Partindo da complexidade do fenômeno da violência contra a mulher, é fundamental uma rede que articule ações entre as diferentes esferas de governo, instituições governamentais e não governamentais e comunidade. O trabalho em rede é o caminho para superar a desarticulação e fragmentação dos serviços e ofertar um atendimento de qualidade, com encami- 
nhamentos adequados e desenvolvimento de estratégias efetivas de prevenção (Brasil, 2011b).

Todavia, de acordo com Presser, Meneghel e Hennington (2008), não há uma única rota ou itinerário ideal, pelo contrário, a rota percorrida pelas mulheres é longa, dolorosa e nem sempre eficiente. Meneghel et al. (2011) apontam que a trajetória das mulheres que decidem romper com a violência é longa, marcada por avanços e retrocessos, desprovida de apoio e, em muitas situações, ocorre revitimização, vivenciada nos próprios serviços onde deveriam receber cuidado e acolhimento.

Um dos elementos que auxilia na compreensão da violência institucional ainda ocasionada às usuárias é apontado por Santos (2015), acerca da formatação das redes de atendimento, bem como das ideologias de seus agentes nas práticas cotidianas dos serviços. Ou seja, a existência de várias redes e diversos graus de articulação entre os serviços, bem como a relação entre as/os agentes dos serviços atravessada por conflitos de abordagens sobre violência doméstica contra mulheres e pela falta de comunicação entre as/os agentes ou falta de conhecimento recíproco, fragilizam a potência transformadora da rede de enfrentamento. Confirma-se na realidade de Natal o encontrado por Santos (2015): os fragmentos da rede nem sempre se cruzam e dependem mais da motivação individual dos agentes nos serviços do que de uma prática institucionalizada de atendimento em rede entre setores e serviços especializados.

Em Natal, observa-se também que as redes primárias das mulheres que chegavam aos serviços encontravam-se fragilizadas, sendo poucas as que conseguiam manter relações consideradas importantes em seu convívio. Isto implica que, nestes casos, o homem era uma das únicas referências e a mulher vivia num delicado estado de isolamento social. Geralmente a procura pelo serviço apenas acontecia quando um ato de extrema gravidade ocorria, como uma agressão física ou ameaça de morte por parte do companheiro, sendo apenas neste momento que elas percebiam que não conseguiriam lidar com a situação sozinhas e procuravam por ajuda.

A dificuldade no acesso aos serviços, porém, continuava sendo um grande obstáculo da atenção nestes casos. De acordo com Silva, Padoin e Vianna (2015), é essencial que haja a consolidação da rede de proteção à mulher, a nível intersetorial, não somente a partir da perspectiva da assistência social ou da segurança pública. Dessa forma, a rede poderia ser acessada pelas usuárias nos vários pontos possíveis, fazendo com que as situações que chegassem aos serviços fossem compartilhadas por todos os envolvidos, nos mais diversos âmbitos de atuação, para que houvesse o seguimento dos casos de modo comprometido e articulado.

Apesar de a Semul atuar há quase 10 anos na implementação e gestão das políticas públicas para as mulheres na cidade de Natal, a definição dos fluxos assistenciais, unificação de campanhas e projetos de diferentes setores da rede local era semelhante ao referido por Kiss, Schraiber e D'Oliveira (2007): com desajuste das ferramentas de trabalho e protocolos incompatíveis entre si, produzindo fluxos assistenciais pouco consistentes, indicando a fragmentação das ações e falta de trabalho em rede. Não fazia parte do cotidiano a realização de reuniões de forma estruturada entre os serviços, ainda que consistisse em uma ferramenta fundamental para a socialização de casos, saberes e questões, garantindo visibilidade e possibilidades de resolução para as situações de violência contra a mulher (Menezes et al., 2014). Os poucos casos que chegavam ao centro de referência, encaminhados pelas Unidades Básicas de Saúde (UBS), Centro de Referência de Assistência Social (CRAS) e Centro de Referência Especializado de Assistência Social (CREAS), terminavam sem o devido acompanhamento da rota percorrida por essas mulheres, culminando numa atenção fragmentada. Diante dessa fragmentação, a institucionalização de reuniões periódicas entre os serviços seria útil nos casos em que profissionais dos outros setores não tivessem conhecimento sobre os dispositivos específicos de atenção à mulher em situação de violência, bem como das atribuições de cada serviço na rede de enfrentamento à violência contra a mulher.

Portanto, em nível municipal é necessário haver maior articulação com o campo da saúde pública, para que esta porta de entrada possa ser cada vez mais qualificada e resolutiva no acolhimento e orientação das mulheres em situação de violência. Esta articulação mostra-se imprescindível, uma vez que a rede de proteção à mulher não possui a capilaridade necessária para identificar e acolher os casos, na mesma proporção, em todas as zonas da cidade. Por isso, destaca-se a importância de empreender cada vez mais estratégias e parcerias em rede para alcançar os territórios que não estão contemplados com equipamentos da Semul. 


\section{As práticas profissionais no cotidiano dos serviços}

\section{Práticas normativas e ideais de eficácia}

As mulheres que chegavam aos serviços de acolhimento apresentavam trajetórias de vida singulares e contextos particulares de existência, o que impunha aos profissionais demandas de diversas ordens. Porém discursos como: "a usuária não teve resistência a se adequar às normas”, “a usuária parece interessada em superar a situação de violência sofrida", "a usuária não deseja retornar para seu agressor" e "apresentou comportamento adequado de convivência na casa", demonstravam implicitamente a expectativa dos profissionais de adequação das usuárias a um modelo de mulher: vitimizada, padronizada e docilizada. Tais posicionamentos levam a questionar: de que forma os profissionais entendem que estão produzindo deslocamentos e ressignificações nas histórias de vida dessas mulheres?

Como é possível notar, esses discursos se amparam, dentre outras coisas, no dualismo vítima-agressor, apesar de ser uma ideia fortemente contestada por diversos autores (Andrade, 2014; Beiras, \& Cantera, 2014; Silva, Coelho \& Njaine, 2014; Silva, \& Oliveira, 2015). São atravessados também pela relação de saber-poder entre usuárias e equipe técnica, cujos atendimentos se produzem e são administrados pelos experts ou "especialistas" - aqueles que "se supõe que saiba e conheça sobre o assunto" (Baremblitt, 2002, p. 15). Neste sentido, definem a quantidade, a qualidade, a necessidade e a conveniência dos serviços prestados nas diversas áreas e, ainda que não utilizem da força física, valem-se da força de persuasão, da sedução.

Partindo do entendimento de que as demandas não partem de necessidades básicas e universais, mas são permanentemente produzidas e moduladas, faz-se importante definir minimamente o que as usuárias realmente aspiram e necessitam, e diferenciar daquilo que as equipes entendem que "elas necessitam e acham que querem e como querem" (Baremblitt, 2002, p. 16). Para muitas dessas mulheres, chegar até o serviço não representava um movimento simples, mas o resultado da pressão da família, dos amigos ou de outros agentes, objetivando oficializar a denúncia e o pedido de separação, para a qual nem sempre tinha convicção. Seja nesses casos ou naqueles de procura espontânea, havia muito sofrimento, dúvida e angústia, os quais demandavam escuta, cui- dado e acolhimento por parte dos profissionais, assim como capacidade de abertura para compreender seu lugar e oferecer o suporte necessário para a tomada de decisões.

No entanto, o acolhimento das mulheres e a condenação dos homens foram, basicamente, os termômetros mais utilizados para identificar e sinalizar o rompimento do ciclo de violência. Os casos de não denúncia já eram considerados pela equipe da rede de Natal, como índices de desinteresse da mulher em sair da situação de violência, o que se acentuava ainda mais nos casos em que elas decidiam retornar à convivência com seus antigos parceiros. Tais decisões repercutiam na equipe quase que invariavelmente como um sentimento de trabalho inútil ou fracasso.

Villela et al. (2011) afirmam que se deve ter em conta que a decisão de denunciar o homem autor de violência é demorada, sendo tomada quando se esgotam as demais alternativas de solução do problema. Portanto, esses autores ajudam a compreender a realidade local, ressaltando que o sentimento de impotência e revolta dos profissionais passa pela não compreensão da situação contraditória vivida pela mulher, a qual se vê maltratada por alguém a quem ama e de quem muitas vezes depende, desconsiderando também importantes elementos como o ideal de casamento e família, acessibilidade a recursos financeiros, quantidade e qualidade do apoio familiar e comunitário, o que interfere diretamente nas possibilidades de decisão que a mulher possui.

Faz-se necessário resgatar o protagonismo das mulheres em suas decisões, distanciando-se da alienação do saber sobre sua "própria vida, a noção de suas reais necessidades, de seus desejos, de suas demandas, de suas limitações e das causas que determinam essas necessidades e essas limitações" (Baremblitt, 2002, p. 17). O Institucionalismo, visando este resgate, utiliza-se de dois processos, que servem de meio e fim para o processo de auto-organização: a autoanálise e a autogestão.

Utilizar estes processos não implica em prescindir por completo dos experts, os quais possuem um relevante conhecimento que pode e deve agregar ao produto dos atendimentos. Porém se trata de inverter a lógica do saber-poder, relativizando "suas glórias, seus métodos, suas técnicas e suas inserções sociais" (Baremblitt, 2002, p. 18), submetendo suas práxis a uma profunda e permanente crítica, a qual possibilite separar "o que é produto de sua origem, de sua per- 
tença ao bloco dominante das forças sociais e o que pode ser útil a uma autoanálise, a uma autogestão, da qual os segmentos dominados e explorados sejam protagonistas" (Baremblitt, 2002, p. 18). No entanto, conforme situa o autor, esses processos autoanalíticos e autogestivos se dão em condições altamente desfavoráveis, uma vez que esses coletivos "não são donos do saber, não são donos da riqueza, não são donos dos recursos" (Baremblitt, 2002, p. 22).

Os processos de autoanálise e autogestão se aplicam sobremaneira ao funcionamento da casa abrigo, uma vez que, como bem refere Tavares (2015), muitas vezes, predomina nesse serviço a lógica do confinamento e da falta de autonomia. Na rede local, confirma-se o encontrado pela autora: a existência de um processo de punição invertida, em que a mulher precisa permanecer presa para garantir sua segurança, enquanto o homem que cometeu o crime permanece livre. Dentre as questões que emergem: como lidam com o sistema de códigos e práticas sociais destas mulheres advindas das periferias? Escapam ao poder normatizador da instituição as possibilidades de uso do próprio corpo e da própria fala ou as mulheres adequam-se à lógica institucional? Como são considerados os sistemas de códigos - tatuagens, gírias, crenças - pela equipe e como manejam os conflitos resultantes da diversidade de experiências entre as mulheres abrigadas?

Essas questões se acentuavam na casa abrigo, já que consistia no local em que se decantavam as práticas cotidianas das usuárias e as contradições das práticas profissionais. $\mathrm{O}$ seu modo de funcionamento mostrou-se coerente ao encontrado por Guirado (2009) quando aponto a verticalidade dos processos de comunicação e de instauração de normas, em que as usuárias precisam seguir uma série de regras impostas, estruturando uma relação de obediência para com os profissionais.

A Casa Abrigo poderia se tornar um espaço privilegiado para a abertura de processos instituintes e criação de dispositivos, a partir de processos autogestivos, desde que favorecesse a "circulação menos restritiva da palavra e de corpos, abrindo as relações para múltiplas conexões potencializadoras da transformação da realidade dos grupos e das subjetividades" (Rossi, \& Passos, 2014, p. 166). No entanto, a hierarquização organizativa do cotidiano quebrava a produção de autonomia e criava barreiras à possibilidade de consolidação da autogestão, processo que poderia embasar a dinâmica de funcionamento dos serviços da rede, sobretudo, da casa abrigo.

\section{Embates da prática psicológica e social}

O estudo conduzido por Hanada, D'Oliveira e Schraiber (2010) demonstra que os psicólogos estão inseridos em praticamente todos os serviços na rede assistencial às mulheres em situação de violência, refletindo a penetrabilidade da profissão neste campo. Pereira e Guareschi (2017) aludem que o advento do Sistema Único de Assistência Social (SUAS) inseriu definitivamente a Psicologia no campo da assistência social, já que a presença de profissionais psicólogos é prevista e obrigatória na composição das equipes, tanto a nível básico, quanto especializado.

Nos vários locais em que atuam - como é o caso dos psicólogos da rede de Natal - o trabalho acontece em equipes multiprofissionais. Embora psicólogos e assistentes sociais partilhem processos de trabalho como atendimentos psicossociais, visitas domiciliares e desenvolvimento de grupos, se nota uma cultura muito frágil de trabalho integrado. Hanada et al. (2010) esclarecem que a mera presença de várias especialidades não garante o trabalho articulado, nem a interação da equipe. Um exemplo disso são as discussões de caso, as quais aconteciam através de conversas informais entre os profissionais, e não como uma ferramenta instituída nas atividades das equipes.

A prática psicológica parecia perder sua definição quando se afastava de suas práticas clínicas tradicionais e adentrava na seara de uma "nova Psicologia" (Yamamoto, \& Oliveira, 2010), implicada politicamente com grupos/populações marginalizadas e em contexto de vulnerabilidade social. Esta nova atuação situada no campo das políticas sociais é atravessada por embates e conflitos, haja vista que o objeto de intervenção denominado genericamente como "social" mostrava-se disputado cotidianamente com os profissionais da assistência social, produzindo uma série de embates, incertezas e inseguranças quanto aos lugares atribuídos à Psicologia e ao serviço social.

Com o esforço de definir quais seriam as competências do psicólogo e assistente social, percebia-se instituída nos discursos e práticas das equipes locais uma clara separação: a Psicologia se centraria nos aspectos comportamentais e nas emoções das mulheres, enquanto o serviço social se voltaria às vulnerabilidades sociais, realizando os encaminhamentos para outros pontos da rede. Ou seja, a Psicologia 
era representada como detentora de um saber-poder sobre aspectos intrapsíquicos, individuais ou, quando muito, acerca das relações interpessoais, o que para Pereira e Guareschi (2017) se torna um risco de psicologizar as questões sociais, caso não apresente como horizonte uma transformação política, ética e social.

\section{Empoderamento e manejo do sofrimento no cotidiano}

Uma compreensão muito comum nas práticas cotidianas dos serviços de proteção à mulher é a promoção de empoderamento. Talvez em parte pela própria diversidade compreensiva, percebe-se uma imprecisão do que seja tal empoderamento. Em muitos casos referem o conceito a ideais de autoeficácia, autonomia, autodeterminação, controle pessoal e autorregulação, atrelando o sentido do termo a um viés individual sobre o próprio comportamento e às dimensões pessoais.

Alguns autores (Cerezo, Juvé-Udina, \& Delgado-Hito, 2016; Marinho, \& Gonçalves, 2016) referem que o termo necessita ser melhor empregado, uma vez que o conceito é próprio da comunidade e não do indivíduo. Marinho e Gonçalves (2016) criticam a compreensão psicológica do termo, segundo um sentimento de controle a respeito da própria vida. Para estes autores, uma vez que esta concepção não se preocupa com a modificação das estruturas sociais, é ilusória, não correspondendo, pois, à existência efetiva do empoderamento, ou seja, só há empoderamento se este for coletivo. Em outros termos, se trata de um processo que parte do enfrentamento de fatores referentes à estrutura de poder presentes na esfera micro e macrossocial, o que consequentemente implica a redistribuição do poder. Isto é, essa redistribuição é processo e resultado da promoção de empoderamento.

O acolhimento também é identificado como um dos maiores objetivos dos atendimentos à mulher em situação de violência na rede de proteção local. Todavia, verificamos a fragilidade no manejo de ferramentas importantes de trabalho como as visitas domiciliares, escuta e acolhimento, trabalho em equipe (reuniões, discussões de caso, gestão de caso), assim como a divulgação do serviço à comunidade. Acerca da qualidade da escuta e do acolhimento, é importante questionar-se cotidianamente: estou disponível e aberto para aceitar o outro em sua singularidade e acolher seu sofrimento? Segundo Lisboa e Pinheiro (2005), o momento da visita domiciliar merece um olhar de destaque por parte dos profissionais, uma vez que ela consiste em um instrumento ímpar para o conhecimento genuíno da realidade das usuárias, permitindo uma compreensão mais aguçada dos diferentes casos que chegam ao serviço, servindo de base para intervenções psicossociais que também devem envolver a família e a vizinhança para melhor acompanhamento da situação.

Silva, Padoin e Vianna (2013) referem o acolhimento como postura e prática promotora da construção relacional de confiança e compromisso dos usuários com as equipes e os serviços, objetivando as respostas resolutivas aos problemas identificados através da escuta. Esse entendimento é a base para uma prática assistencial mais assertiva à mulher em situação de violência. Os autores compreendem o acolhimento a partir de três dimensões: postura, técnica e de reorientação dos serviços. Integra-se a esses planos a noção de humanização nas relações entre trabalhadores e usuários. Situam que "o acolhimento é incorporado à acessibilidade organizacional, que, por sua vez, deve ter estratégias que facilitem a entrada da usuária no Serviço" (p. 611). Faz-se, pois, essencial que a mulher perceba que o serviço se interessa pelo seu problema e que a equipe deseja apoiá-la no enfrentamento.

Silva et al. (2013) entendem que o acolhimento, como postura, deve acontecer em qualquer local e em qualquer momento da prática, sempre respeitando a decisão da própria mulher, assim sendo, "orientações como a denúncia do agressor, medidas protetivas como o afastamento dele da casa e o apoio de instituições são informações que ela precisa receber, mas a decisão final é dela" (p. 611). Tendo em vista que permanece cristalizado o ideal do homem autor de violência como opressor, agressor e que, portanto, merece ser descartado como elemento indesejável no produto dos atendimentos, estes autores reafirmam que os profissionais "precisam estar preparados para compreender a perspectiva da mulher e, assim, incluir o agressor no plano de enfrentamento, deixando o aspecto punitivo e educativo da legislação para outro momento da assistência" (Silva et al., 2013, p. 611). Por fim, defendem que, tendo em vista a diversidade de situações de violência, a necessidade de planos de solução distintos, de forma que um protocolo padrão e fixo não seria recomendado. Neste intuito, a escuta qualificada seria alcançada a partir de tecnologias leves que considerem a inter-relação e intersubjetividades para com a usuária. 


\section{Considerações finais}

De acordo com Cordeiro e Curado (2017), uma boa formação em Psicologia deve dar condições para que psicólogas(os) possam, de maneira criativa e inventiva, produzir saberes e práticas situados. Nesse processo, os estágios supervisionados são de valor inestimável, posto que "permitem um contato inicial com as realidades, com as práticas, dificuldades e lógicas que permeiam o trabalho na Assistência Social" (Cordeiro, \& Curado, 2017, p. 5). Não obstante, segundo Cordeiro e Curado (2017), os cursos de graduação em Psicologia, em geral, oferecem uma formação deficitária para o trabalho no campo das políticas sociais, haja vista a ênfase dada às práticas clínicas - "práticas essas que tendem a reproduzir o modelo hegemônico de intervenção psicológica, voltado às populações social e economicamente favorecidas" (p. 4).

Santos e Nóbrega (2017) acrescentam que os cursos privilegiam saberes cuja ênfase recai sobre a técnica em detrimento de uma reflexão crítica e uma prática política, dificultando a interlocução entre teoria e prática nos cenários sociais precarizados. É válido ressaltar que esta lacuna formativa, apesar de atravessar a formação de muitos psicólogos, não fez parte da nossa experiência enquanto discentes e estagiários no curso da UFRN, o qual dispõe de diversos componentes curriculares, grupos de pesquisa e atividades de extensão implicados com o Compromisso Social da Psicologia, de transformação social e ampliação dos Direitos Humanos.

Esta experiência de estágio demonstrou que o acolhimento e a escuta são práticas atribuídas por outros profissionais como de exclusividade do psicólogo, que fica com a responsabilidade de lidar com o sofrimento das mulheres em situação de violência. Entretanto, o acolhimento pressupõe o estabelecimento de colaboração multidisciplinar e interprofissional (Signorelli, Taft, \& Pereira, 2018) e deve ir além do senso comum e da empatia, o que torna indispensável repensar e qualificar as formas de acolhimento às mulheres em situação de violência. Um passo importante nesse sentido é atentar para as posturas moralizantes e prescritivas, bem como para a perspectiva reducionista, calcada nos tradicionais papéis de vítima e agressor. Ademais, deve-se compreender a violência a partir de uma perspectiva mais abrangente, ressaltando seu enfoque relacional, interseccional e de gênero.

No que concerne ao trabalho em equipe, verifica-se que não existem diretrizes específicas nas Diretrizes Nacionais para o Abrigamento (Brasil, 2011a) ou mesmo nas Normas Técnicas de Uniformização dos Centros de Referência (Brasil, 2006), o que torna esses materiais mais uma fonte de inspiração do que propriamente uma orientação concreta (Cordeiro, \& Curado, 2017). Por fim, acerca dos fluxos e articulação em rede, destaca-se a importância de fortalecer o trabalho de formas inter e intrasetorial, para que seja possível produzir deslocamentos efetivos nas histórias de vida das mulheres que acessam os serviços. Para o alcance de tais objetivos, faz-se necessário que o cotidiano de trabalho seja repensado no interior dos serviços promovendo práticas sensíveis aos diferentes contextos e à realidade dessas mulheres.

\section{Referências}

Andrade, A. G. S., \& Morais, N. A. (2017). Avaliação do atendimento recebido no CRAS por famílias usuárias. Psicologia: Ciência e Profissão, 37(2), 378-392. https://doi.org/10.1590/1982-3703001412016

Andrade, L. F. (2014). Grupos de homens e homens em grupos: Novas dimensões e condições para as masculinidades. In E. A. Blay (Org.), Feminismos e masculinidades: Novos caminhos para enfrentar a violência contra a mulher (pp. 173-210). São Paulo, SP: Cultura Acadêmica.

Baremblitt, G. F. (2002). Compêndio de análise institucional e outras correntes: Teoria e prática (5a ed.). Belo Horizonte, MG: Instituto Felix Guattari.

Barufaldi, L. A., Souto, R. M. C. V., Correia, R. S. B., Montenegro, M. M. S., Pinto, I. V., Silva, M. M. A. et al. (2017). Violência de gênero: Comparação da mortalidade por agressão em mulheres com e sem notificação prévia de violência. Ciência \& Saúde Coletiva, 22(9), 2929-2938. https://doi.org/10.1590/1413-81232017229.12712017

Beiras, A., \& Canteira, L. M. (2014). Feminismo pós-estruturalista e masculinidades: Contribuições para a intervenção com homens autores de violência. In E. A. Blay (Org.), Feminismos e masculinidades: Novos caminhos para enfrentar a violência contra a mulher (pp. 29-44). São Paulo, SP: Cultura Acadêmica.

Brasil (2006). Secretaria Especial de Políticas para as Mulheres. Norma técnica de uniformização: Centros de referência de atendimento à mulher em situação de violência. Brasília, DF: o autor. 
Brasil (2011a). Secretaria Especial de Políticas para as Mulheres. Rede de enfrentamento à violência contra as mulheres. Brasília, DF: o autor.

Brasil (2011b). Secretaria Especial de Políticas para as Mulheres. Diretrizes nacionais para o abrigamento de mulheres em situação de risco e violência. Brasília, DF: o autor. Era a

Brasil (2017). Secretaria da Transparência. Violência doméstica e familiar contra a mulher: Pesquisa datasenado. Brasília, DF: o autor.

Carmo-Souza, T. M., \& Faria, J. S. (2017). Descrição dos serviços de psicologia em delegacias especializadas de atendimento às mulheres no Brasil. Avances en Psicología Latinoamericana, 35(2), 253-265. https://doi.org/10.12804/revistas.urosario.edu.co/apl/a.3687

Cerezo, P. G., Juvé-Udina, M. E., \& Delgado-Hito, P. (2016). Concepts and measures of patient empowerment: A comprehensive review. Revista da Escola de Enfermagem, 50(4), 664-671. https://doi.org/10.1590/S0080-623420160000500018

Cerqueira, D., Lima, R. S., Bueno, S., Neme, C., Ferreira, H., Coelho, D. et al. (2018). Atlas da violência. Rio de Janeiro, RJ: Instituto de Pesquisa Econômica Aplicada. Recuperado de http://www.ipea.gov.br/portal/images/stories/ PDFs/relatorio_institucional/180604_atlas_da_violencia_2018.pdf

Cordeiro, M. P., \& Curado, J. C. (2017). Psicologia na assistência social: Um campo em formação. Psicologia \& Sociedade, 29, 1-11. https://doi.org/10.1590/1807-0310/2017v29169210

Garcia, L. P., \& Silva, G. D. M. (2016). Mortalidade de mulheres por agressões no Brasil: Perfil e estimativas corrigidas (2011-2013). Rio de Janeiro, RJ: Instituto de Pesquisa Econômica Aplicada. Recuperado de http://repositorio. ipea.gov.br/bitstream/11058/6260/1/td_2179.pdf.

Guirado, M. (2009). Psicologia institucional: O exercício da psicologia como instituição. Interação em Psicologia, 13(2), 323-333.

Hanada, H., D’Oliveira, A. F. P. L., \& Schraiber, L. B. (2010). Os psicólogos na rede de assistência a mulheres em situação de violência. Revista Estudos Feministas, 18(1), 33-60. https://doi.org/10.1590/S0104-026X2010000100003

Kiss, L. B., Schraiber, L. B., \& D'Oliveira, A. F. P. L. (2007). Possibilidades de uma rede intersetorial de atendimento a mulheres em situação de violência. Interface - Comunicação, Saúde, Educação, 11(23), 485-501. https://doi.org/10.1590/S1414-32832007000300007

Krenkel, S., \& Moré, C. L. O. O. (2017). Violência contra a mulher, casas-abrigo e redes sociais: Revisão sistemática da literatura. Psicologia: Ciência e Profissão, 37(3), 770-783. https:// doi.org/10.1590/1982-3703000192016

Lisboa, T. K., \& Pinheiro, E. A. (2005). A intervenção do serviço social junto à questão da violência contra a mulher. Katálysis, 8(2), 199-210. https://doi.org/10.1590/\%25x

Marinho, P. A. S., \& Gonçalves, H. S. (2016). Práticas de empoderamento feminino na América Latina. Revista de Estudios Sociales, (56), 80-90. https://doi.org/10.7440/res56.2016.06

Meneghel, S. N., Bairros, F., Mueller, B., Monteiro, D., Oliveira, L. P., \& Collaziol, M. E. (2011). Rotas críticas de mulheres em situação de violência: Depoimentos de mulheres e operadores em Porto Alegre, Rio Grande do Sul, Brasil. Caderno de Saúde Pública, 27(4), 743-752. https://doi.org/10.1590/S0102-311X2011000400013

Menezes, P. R. M., Lima, I. S., Correia, C. M., Souza, S. S., Erdmann, A. L., \& Gomes, N. P. (2014). Enfrentamento da violência contra a mulher: Articulação intersetorial e atenção integral. Saúde e Sociedade, 23(3), 778-786. https://doi.org/10.1590/S0104-12902014000300004

Moura, M. A.V., Netto, L. A., \& Souza, M. H. N. (2012). Perfil sociodemográfico de mulheres em situação de violência assistidas nas delegacias especializadas. Escola Anna Nery, 16(3), 435-442. https://doi.org/10.1590/S1414-81452012000300002

Organização dos Estados Americanos - OEA. (1994). Convenção interamericana para prevenir, punir e erradicar a violência contra a mulher. Belém, PA: o autor. Recuperado de http://www.pge.sp.gov.br/centrodeestudos/bibliotecavirtual/instrumentos/belem.htm

Pasinato, W. (2015). Oito anos de lei Maria da Penha: Entre avanços, obstáculos e desafios. Revista Estudos Feministas, 23(2), 533-545. https://doi.org/10.1590/0104-026X2015v23n2p533

Pereira, V. T., \& Guareschi, P. A. (2017). A psicologia no CRAS: Um estudo de representações sociais. Psicologia \& Sociedade, 29, 1-11. https://doi.org/10.1590/1807-0310/2017v29119584 
Piosiadlo, L. C. M., Fonseca, R. M. G. S., \& Gessner, R. (2014). Subalternidade de gênero: Refletindo sobre a vulnerabilidade para violência doméstica contra a mulher. Escola Anna Nery, 18(4), 728-733. https:// doi.org/10.5935/1414-8145.20140104

Presser, A. D., Meneghel, S. N., \& Hennington, E. A. (2008). Mulheres enfrentando as violências: A voz dos operadores sociais. Saúde e Sociedade, 17(3), 126-137. https:// doi.org/10.1590/S0104-12902008000300013

Rafael, R. M. R., Moura, A. T. M. S., Tavares, J. M. C., Ferreira, R. E. M., Camilo, G. G. S., \& Neto, M. (2017). Perfil das violências por parceiro íntimo em Unidades de Saúde da Família. Revista Brasileira de Enfermagem, 70(6), 12591267. https://doi.org/10.1590/0034-7167-2016-0007

Romagnoli, R. C. (2015). A violência contra a mulher em Montes Claros. Barbarói, 43(1), 27-47. https://doi.org/10.17058/barbaroi.v0i0.4815

Rossi, A., \& Passos, E. (2014). Análise institucional: Revisão conceitual e nuances da pesquisa-intervenção no Brasil. Revista EPOS, 5(1), 156-181.

Santos, A. C., \& Nóbrega, D. O. (2017). Dores e delícias em ser estagiária: O estágio na formação em psicologia. Psicologia: Ciência e Profissão, 37(2), 515-528. https://doi.org/10.1590/1982-3703002992015

Santos, C. M. (2015). Curto-circuito, falta de linha ou na linha? Redes de enfrentamento à violência contra mulheres em São Paulo. Revista Estudos Feministas, 23(2), 577-600. https://doi.org/10.1590/0104-026X2015v23n2p577

Santos, P. A. C., Souza, A. V. M., \& Santos, V. S. (2001). O conceito de implicação em práticas da análise institucional contemporânea. In Colóquio Internacional "Educação e Contemporaneidade", São Cristovão, SP, Brasil, 5. Recuperado de http://educonse.com.br/2011/

Signorelli, M. C., Taft, A., \& Pereira, P. P. G. (2018). Domestic violence against women, public policies and community health workers in brazilian primary health care. Ciência \& Saúde Coletiva, 23(1), 93-102. https://doi.org/10.1590/1413-81232018231.16562015

Silva, A. C. L. G., Coelho, E. B. S., \& Njaine, K. (2014). Violência conjugal: As controvérsias no relato dos parceiros íntimos em inquéritos policiais. Ciência \& Saúde Coletiva, 19(4), 1255-1262. https://doi.org/10.1590/1413-81232014194.01202013

Silva, E. B., Padoin, S. M. M., \& Vianna, L. A. C. (2015). Mulher em situação de violência: Limites da assistência. Ciência \& Saúde Coletiva, 20(1), 249-258. https://doi.org/10.1590/1413-81232014201.21202013

Silva, E. B., Padoin, S. M. M., \& Vianna, L. A. C. (2013). Violência contra a mulher: Limites e potencialidades da prática assistencial. Acta Paulista de Enfermagem, 26(6), 608-603. https:// doi.org/10.1590/S0103-21002013000600016

Silva, L. E. L., \& Oliveira, M. L. C. (2015). Violência contra a mulher: Revisão sistemática da produção científica nacional no período de 2009 a 2013. Ciência \& Saúde Coletiva, 20(11), 3523-3532. https://doi.org/10.1590/1413-812320152011.11302014

Tavares, M. S. (2015). Roda de conversa entre mulheres: Denúncias sobre a lei Maria da Penha e descrença na justiça. Estudos Feministas, 23(2), 547-559. https://doi.org/10.1590/0104-026X2015v23n2p547

Trentin, D., Vargas, M. A. O., Pires, D. E. P., Hellmann, F., Brehmer, L., \& Leal, S. C. (2018). Abordagem a mulheres em situação de violência sexual na perspectiva da bioética. Acta Bioethica, 24(1), 117-126. https://doi.org/10.4067/S1726-569X2018000100117

Villela, W. V., Vianna, L. A. C., Lima, L. F. P., Sala, D. C. P., Vieira, T. F, Vieira, M. L. et al. (2011). Ambiguidades e contradições no atendimento de mulheres que sofrem violência. Saúde e Sociedade, 20(1), 113-123. https://doi.org/10.1590/S0104-12902011000100014

Waiselfisz, J. J. (2015). Mapa da violência 2015: Homicídios de mulheres no Brasil. Rio de Janeiro, RJ: Faculdade Latino-Americana de Ciências Sociais. Recuperado de http://www.mapadaviolencia.org.br/mapa2015_ mulheres.php

World Health Organization -WHO. (2013). Global and regional estimates of violence against women: Prevalence and health effects of intimate partner violence and nonpartner sexual violence. Genebra: o autor.

Yamamoto, O. H., \& Oliveira, I. F. (2010). Política social e psicologia: Uma trajetória de 25 anos. Psicologia: Teoria e Pesquisa, 26(esp.), 9-24. https://doi.org/10.1590/S0102-37722010000500002 
Victor Hugo Belarmino

Mestre em Psicologia pela Universidade Federal do Rio Grande do Norte, Natal - RN. Brasil.

E-mail: victorbelarmino@outlook.com

(iD) https://orcid.org/0000-0002-4102-3351

Janine Conceição de Araújo e Silva

Especialista em Terapia Intensiva Neonatal - Natal-RN. Brasil. Psicóloga pela Universidade Federal do Rio Grande do Norte, Natal - RN. Brasil.

E-mail: janinearaujo02@gmail.com

(iD) https://orcid.org/0000-0003-0747-5503

Letícia Lívia de Araújo Santos

Especialista em Atenção Básica, pela Universidade Federal do Rio Grande do Norte, Natal - RN. Brasil. Psicóloga pela Universidade Federal do Rio Grande do Norte, Natal - RN. Brasil.

E-mail: leticia.livia.s@gmail.com

(iD https://orcid.org/0000-0002-6619-2450

Magda Dimenstein

Professora titular do Departamento de Psicologia da Universidade Federal do Rio Grande do Norte, Natal - RN. Brasil.

E-mail: mgdimenstein@gmail.com

(iD https://orcid.org/0000-0002-5000-2915

Endereço para envio de correspondência:

Universidade Federal do Rio Grande do Norte, CCHLA, Departamento de Psicologia, Campus Universitário, Lagoa Nova. CEP: 59078-970. Natal - RN. Brasil.

Recebido 21/05/2018

Reformulado 21/02/2019

Aceito 22/03/2019

Received $05 / 21 / 2018$

Reformulated $02 / 21 / 2019$

Approved 03/22/2019

Recibido 21/05/2018

Reformulado 21/02/2019

Aceptado 22/03/2019 
Como citar: Belarmino, V. H., Silva, J. C. A., Santos, L. L. A., \& Dimenstein, M. (2020). Reflexões sobre práticas e cotidiano institucional na Rede de Proteção à Mulher. Psicologia: Ciência e Profissão, 40, 1-12. https://doi.org/10.1590/1982-3703003200160

How to cite: Belarmino, V. H., Silva, J. C. A., Santos, L. L. A., \& Dimenstein, M. (2020). Reflections on practices and the institutional daily life in the Women's Protection Network. Psicologia: Ciência e Profissão, 40, 1-12. https://doi.org/10.1590/1982-3703003200160

Cómo citar: Belarmino, V. H., Silva, J. C. A., Santos, L. L. A., \& Dimenstein, M. (2020). Reflexiones sobre prácticas y vida cotidiana institucional en la Red de Protección a la Mujer. Psicologia: Ciência e Profissão, 40, 1-12. https://doi.org/10.1590/1982-3703003200160 